\title{
AOTrauma-ORP-Jahrestagung 2018
}

Alexander Motzny

\section{Die AOTrauma-Jahrestagung des OP-Pflegepersonal-Teams fand vom 15. bis 17. Fe- bruar 2018 wieder in der Berufsgenossenschaftlichen Unfallklinik in Tübingen statt.}

Die AOTrauma-ORP-Gruppe betreut gemeinsam mit den ärztlichen, wissenschaftlichen Leitern vor Ort alle AOTrauma- und AOCMF-Kurse für OP-Pflegepersonal in Deutschland. Dies sind 7-8 Basis- und Fortgeschrittenenkurse plus 4 AOTrauma-ORP-Tage über das ganze Jahr verteilt.

Alexander Motzny, als derzeitiger Mentor der AOTraumaORP-Gruppe Deutschland, hatte zusammen mit Professor Ulrich Stöckle, dem Ärztlichen Direktor und Schatzmeister der Deutschen AOTrauma, zum Treffen eingeladen.

Im Vordergrund des Treffens standen die gemeinsame Fertigstellung und Weiterentwicklung von PowerPointPräsentationen für die Diskussionsgruppen bei den Kursen in Zusammenarbeit mit dem Coach der Gruppe, Professor Peter Strohm aus Bamberg.

Ein weiterer wichtiger Baustein bei der Tagung war das Vortragen von Präsentationen durch einzelne Mitglieder im Sinne von „Teaching the Teachers“. Hierbei sollen nicht nur neue Mitglieder im geschützten Umfeld die Möglichkeit bekommen, sich zu präsentieren und durch den Coach und die Gruppe Feedback zu erhalten, sondern auch langjährige Mitglieder bekamen Feedback über ihre Präsentationen und ihre Präsentationstechnik.

Weiterhin fand ein Austausch mit dem Logistikpartner DPS statt, bei dem hauptsächlich administrative Belange wie Kursbewerbung und Kursgebühren besprochen wurden.

Neuigkeiten aus dem zentralen ORP-Team in Davos berichtete Elke Zaiss, Berlin, die sie von ihrem AOT Educators Seminar in Davos letzten Dezember mitbrachte. Sie informierte auch über die Entwicklungen bei den CTM (Clinical Training Moduls).

Alexander Motzny berichtete aus den Gremiensitzungen der Deutschen AO, an denen er als ORP-Vertreter seit 2017 teilnimmt.

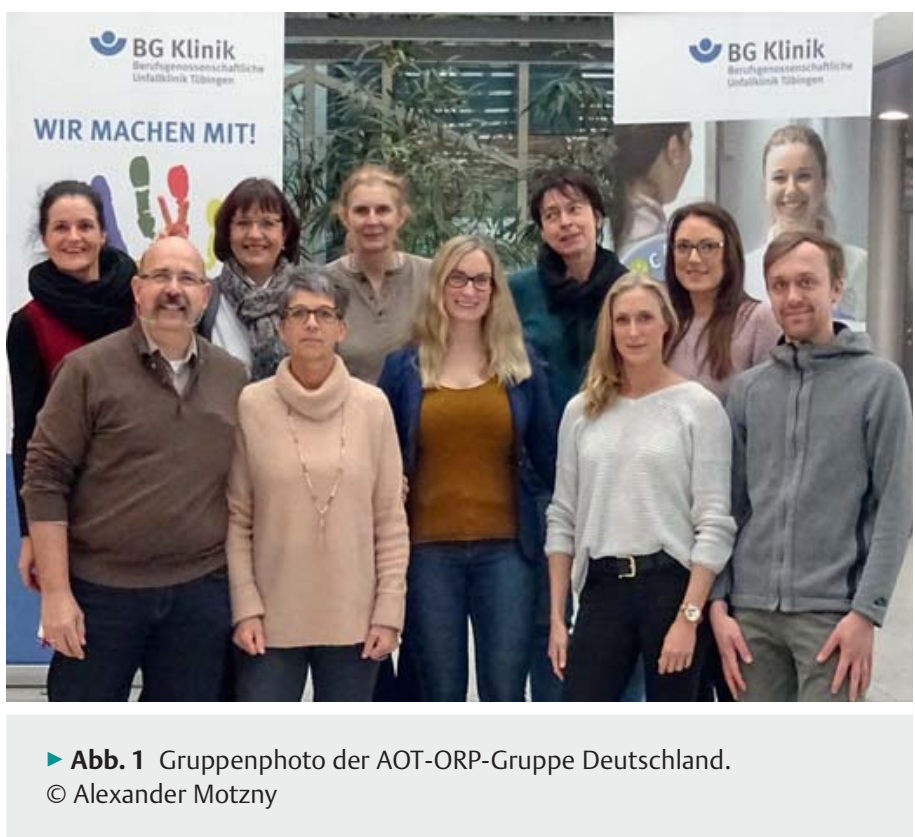

Der Rest der Tagung war gefüllt mit Administrativem, Planung und Abstimmung der Kurse 2018/19 und der Planung der erstmaligen Teilnahme der ORP-Gruppe am AOTrauma D-A-CH Meeting in Hamburg 2019.

Das Jahrestreffen hat erneut gezeigt, wie wichtig solche Treffen für die Kommunikation und Weiterentwicklung der ORP-Gruppe sind. Motivierte OP-Mitarbeiter/innen mit Lust zur Mitarbeit sind herzlich eingeladen, bei uns mitzuwirken.

Alexander Motzny, Tübingen

E-Mail: amotzny@bgu-tuebingen.de

Bibliografie

DOI https://doi.org/10.1055/a-0591-2100

OP-JOURNAL 2018; 34: 71 @ Georg Thieme Verlag KG Stuttgart · New York ISSN 0178-1715 